\title{
TRADUÇÃO AUDIOVISUAL: ESTUDOS SOBRE A LEITURA DE LEGENDAS PARA SURDOS E ENSURDECIDOS
}

\author{
Patrícia Araújo Vieira 1 \\ ${ }^{1}$ Universidade Federal do Ceará, Fortaleza, Ceará, Brasil \\ Ítalo Alves Pinto de Assis-2 \\ Vera Lúcia Santiago Araújo ${ }^{2}$ \\ ${ }_{2}^{2}$ Universidade Estadual do Ceará, Fortaleza, Ceará, Brasil
}

\begin{abstract}
Resumo: Este artigo é uma revisão de literatura sobre as pesquisas desenvolvidas pelos pesquisadores do grupo LEAD (Legendagem e Audiodescrição) da Universidade Estadual do Ceará (UECE) sobre a leitura de legendas por espectadores surdos e ensurdecidos em meios audiovisuais. Estes estudos têm como suporte teórico-metodológico a Tradução Audiovisual Acessível (TAVa) e buscam um modelo de Legendagem para Surdos e Ensurdecidos (LSE) que atenda às necessidades dos espectadores surdos e ensurdecidos, contribuindo para a formação de legendistas e para a acessibilidade dos programas audiovisuais brasileiros. Dessa forma, nosso objetivo tem sido investigar como os parâmetros em legendagem, validados pela literatura da área, influenciam o processamento de legendas por espectadores surdos e ensurdecidos. As metodologias vão desde estudos exploratórios a experimentais baseados no uso de rastreamento ocular. Os mais recentes resultados têm demonstrado que os surdos conseguem processar legendas em velocidade consideradas altas (180 palavras por minuto), desde que o parâmetro de segmentação linguística na quebra de linhas das legendas siga o mais alto nível sintático, conforme já preconizavam os teóricos Karamitroglou e Diaz Cintas e Remael.
\end{abstract}

Palavras-chave: Tradução Audiovisual Acessível; Legendagem para Surdos e Ensurdecidos; Leitura de Legendas; Rastreamento Ocular 


\title{
AUDIOVISUAL TRANSLATION: STUDIES ON READING OF SUBTITLING FOR DEAF AND HARD-OF-HEARING
}

\begin{abstract}
This paper is a literature review on research conducted by members of the group LEAD (Subtitling and Audio description) from the State University of Ceará (UECE) on reading of subtitles by deaf and hard-of-hearing viewers of audiovisual media. These studies are within the theoretical and methodological framework of Acessible Audiovisual Translation (AAVT) and seek a model of Subtitling for the Deaf and Hard-of-Hearing (SDH) that meets the needs of deaf and hard-of-hearing viewers, contributing to the training of subtitlers and to the accessibility of Brazilian audiovisual media. Likewise, our objective has been to explore how subtitling parameters, validated by the literature of this field, influence the processing of subtitles by deaf and hard-of-hearing viewers. The methodologies of these studies range from exploratory to experimental ones based on eye tracking. The most recent results have showed that deaf viewers can process subtitles at what is considered to be a fast rate (180 words per minute) if the parameter of segmentation between line breaks takes place at the highest syntactic node possible, according to what has been attested by the theorists Karamitroglou and Diaz Cintas and Remael. Keywords: Accessible Audiovisual Translation; Subtitling for the Deaf and Hard-of-hearing; Reading of Subtitles; Eye Tracking
\end{abstract}

\section{Introdução}

As modalidades de Tradução Audiovisual (legendagem, legendagem para surdos e ensurdecidos, voice-over, interpretação e audiodescrição) parecem carregar uma similaridade em sua constituição: grande parte dos seus parâmetros foram definidos por profissionais da área, no entanto, carecem de estudos mais profundos que confirmem ou refutem a relevância de seus parâmetros no processamento dessas modalidades de tradução. Logo, para as modalidades de tradução audiovisual que têm ocupado um espaço cada vez mais considerável no mercado e enquanto objeto de estudo teórico, como a Legendagem para Surdos e Ensurdecidos (LSE) e a Audiodescrição (para pessoas cegas), que se filiam a uma subárea 
chamada Tradução Audiovisual Acessível (TAVa), essa discussão torna-se ainda mais relevante.

O relativo crescimento da LSE tem ocorrido a partir da pressão exercida por grupos de surdos/ensurdecidos em torno da necessidade de acessibilidade à informação como necessária para o engajamento desses grupos na sociedade (Diaz Cintas \& Remael). Essa pressão vem mostrando resultados com a legislação de vários países regulamentando a prática e estipulando uma parte (quando não toda) da programação em TV com LSE.

Dessa forma, pela relevância social que esse tema apresenta, melhorias na confecção da LSE vêm sendo investigadas por pesquisas acadêmicas no exterior e no Brasil para que o processamento durante a leitura dessa legenda ocorra de maneira mais confortável. A partir desse contexto, o presente trabalho tem como objetivo discutir os parâmetros técnicos e linguísticos da legendagem e em que medida eles podem proporcionar um processamento menos custoso das legendas por espectadores surdos. Para tal, faremos uma discussão: i) dos parâmetros conforme são apregoados na literatura da área (alguns orientados mais pela prática do que embasados por pesquisas); ii) do contexto da pesquisa exploratória sobre LSE no Brasil e iii) dos parâmetros da legendagem investigados pelo rastreamento ocular.

O presente trabalho está dividido da seguinte maneira: na seção 2 , discutimos aspectos inerentes à natureza da legendagem, enfatizando os parâmetros técnicos, linguísticos e paralinguísticos que a constituem, dando ênfase a questões relacionados à LSE; na seção 3, abordaremos as pesquisas exploratórias com LSE realizadas no âmbito do Grupo LEAD (Legendagem e Audiodescrição) da Universidade Estadual do Ceará (UECE) e os seus resultados sobre as preferências de legendagem para os surdos brasileiros; na seção 4, discutimos os resultados da pesquisa experimental com a LSE usando a técnica do rastreamento ocular. 


\section{Sobre a natureza da legendagem}

Segundo a classificação proposta por Jakobson para os tipos de tradução, o tipo de legendagem mais presente em filmes e programas de TV pode ser classificado como um tipo de tradução interlinguística. Nesse tipo de operação tradutória, o produto audiovisual legendado apresenta em sua banda sonora os diálogos em língua estrangeira e a tradução em texto escrito na língua materna do espectador $^{1}$. Nesse produto audiovisual, dessa forma, há três fontes de informação que se sobrepõem: a imagem visual, os diálogos em língua estrangeira e as legendas em língua materna, de forma que a informação presente nas legendas deva coincidir, de forma ideal, com a informação presente nos diálogos (De Bruycker \& d'Ydewalle).

A legendagem é um tipo especial de tradução audiovisual que apresenta em sua natureza características que a restringem de acordo com seu gênero, espaço, tempo, sincronização e outras características técnicas que estão conectadas à sua distribuição e leitura (readability) (Ghia), além de questões linguísticas e paralinguísticas que também estão envolvidas nesse processo (Araújo \& Assis). Neves cita Baker et al. quando explica sobre os fatores que envolvem a prática da legendagem. Para Baker et al., a necessidade de se aplicar todas essas questões faz com que esse tipo de tradução consista de equilíbrios entre o tempo de leitura, a equivalência da tradução, os objetivos do programa e as especificidades do público-alvo.

Como já explícito no nome, a Legendagem para Surdos e Ensurdecidos (LSE) contempla o público que se encontra nesta condição fazendo com que os mesmos tenham acesso à informação veiculada pelo canal oral por meio do texto escrito em legendas (Araújo \& Assis).

Enquanto a legendagem interlinguística é normalmente associada ao público ouvinte, a LSE ocorre, principalmente, de forma

\footnotetext{
${ }^{1}$ Existe, também, um tipo de legendagem interlinguística chamada de legendagem reversa (De Bruycker \& d'Ydewalle), em que o áudio do filme está em língua materna e a legenda em língua estrangeira.
}

Cad. Trad., Florianópolis, v. 40, nº esp. 2, p. 97-124, set-dez, 2020. 
intralinguística, ou seja, dentro de uma mesma língua, a tradução acontece do canal oral para o canal escrito (Jakobson). Contudo, também pode se apresentar como interlinguística, de uma língua para outra, mas ainda do oral para o escrito, nos casos em que é feita a partir de filmes e programas de TV em língua estrangeira (Assis).

A natureza plurissemiótica da LSE ainda contempla uma operação tradutória de tipo intersemiótioca, encerrando em si possibilidades para os três tipos de tradução descritos por Jakobson. Por englobar também a tradução de ruídos e música (não-verbal quando do tipo instrumental), pode-se dizer que a LSE é intersemiótica pois

\begin{abstract}
[...] os efeitos sonoros são organizados como meio semiótico distinto do linguístico e, dessa forma, há, ao se traduzir sons em palavras, uma operação tradutória que perpassa dois meios semióticos (Assis 25-26).
\end{abstract}

Todos os aspectos da natureza da legendagem interlinguística supracitados também entram em jogo na LSE. Devido à similaridade de constituição e de utilização por diversos públicos e para diversos fins, Szarkowska e Gerber-Morón, em um estudo sobre a recepção de legendas de duas e três linhas por espectadores ouvintes e surdos/ensurdecidos de várias nacionalidades, decidiram, por exemplo, não diferenciar a legendagem para ouvintes da LSE. As autoras fizeram isso, motivadas pelo fato de que as diferenças entre esses tipos de legenda e seus respectivos públicos-alvo estão cada vez menos evidentes, com muitas características que se cruzam².

Como supracitado, existem recursos semióticos que entram em jogo durante a recepção de um produto legendado que não estão

\footnotetext{
${ }^{2}$ Como exemplo para isso, citam os casos de surdos e ensurdecidos britânicos que utilizam legenda para ouvintes sem tradução de ruídos e música; surdos poloneses que utilizam legendas interlinguísticas de filmes lançados em DVD/VOD (quando não há LSE disponível). Além desses casos, as autoras ainda citam ouvintes que fazem uso de LSE para estudar uma língua estrangeira ou em ambientes barulhentos (Szarkowska; Gerber-morón 1-2).
} 
relacionados propriamente ao caráter verbal da língua do texto de partida e que devem ser explicitados para o público surdo para que possa fazer significado no texto de chegada da tradução. Essas características, também chamadas de informações adicionais, são características da LSE. Estes são: a identificação dos falantes, tradução dos efeitos sonoros (música e ruídos) e das características prosódicas da fala. Além dessas informações adicionais, as quais também podem ser nomeadas como paralinguísticas, segundo Assis, questões de ordem técnica e concepções distintas de tradução são aspectos que diferenciam a LSE da legendagem para ouvintes (Araújo \& Nascimento).

Com exceção das informações adicionais, os outros parâmetros da legendagem, divididos em linguísticos e técnicos, são basicamente os mesmos entre legendagem para ouvintes e LSE. Na próxima seção, serão apresentados os parâmetros mais relevantes para a leitura de legendas.

\subsection{Os Parâmetros linguísticos da legendagem}

Sobre os parâmetros linguísticos apregoados nos manuais da legendagem (Diaz Cintas \& Remael), podemos enumerar a redução (parcial e total), coesão, coerência e segmentação linguística enquanto características que têm influência no processamento de legendas, podendo dificultar ou facilitar a compreensão do espectador.

No que diz respeito à redução, esta ocorre a partir das limitações do texto legendado em termos de espaço e tempo. Sobre isso, Diaz Cintas e Remael (145) apontam que "a versão escrita da fala em legendas é quase sempre uma versão reduzida do texto de partida oral $^{3}$ ". Tentar transcrever de forma literal tudo o que é dito em tela é uma das grandes discussões na prática da $\mathrm{LSE}^{4}$ (Szarkowska

\footnotetext{
${ }^{3}$ Nossa tradução de: The written version of speech in subtitles is nearly always a reduced form of the oral $S T$.

4 Sendo lugar de controvérsia quando se trata de LSE, duas opiniões divergem sobre o lugar da edição de texto nesse tipo de legenda. Se, de um lado, os surdos defendem a presença de legendas verbatim para que tenham acesso completo ao
}

Cad. Trad., Florianópolis, v. 40, $\mathrm{n}^{0}$ esp. 2, p. 97-124, set-dez, 2020. 
et al.), prática chamada de legenda verbatim. Na LSE praticada na TV do Brasil, normalmente é feita a transcrição literal da fala em tela, condizendo com o que Araújo (61) chama de "erro de concepção de tradução ${ }^{5}$ " e que é norteado pelas normas que regulamentam a prática desse tipo de legendagem. A portaria 310 do Ministério das Comunicações, por exemplo, descreve a legenda oculta (tipo de LSE veiculada na TV também chamada de closed caption) assim:

\subsection{Legenda Oculta: corresponde à transcrição, em língua portuguesa, dos diálogos, efeitos sonoros, sons do ambiente e demais informações que não poderiam ser percebidos ou compreendidos por pessoas com deficiência auditiva. ( $\mathrm{s} / \mathrm{p}$ )}

Graças à constituição plurissemiótica do produto audiovisual legendado, é possível acessar o texto "perdido" a partir dos canais de informação que operam paralelamente de forma simultânea (Ghia). Dito isto, esta redução pode ser do tipo parcial ou total, sendo que estas duas formas de tradução podem ser utilizados ao mesmo tempo e são parâmetros que constituem a reescrita característica da legendagem (Diaz Cintas \& Remael).

A redução parcial é feita por meio de estratégias de condensação do texto de partida, que implicam uma versão mais curta no texto de chegada. Essas reformulações, que devem ser idiomáticas,

texto de partida, que, "[...] quando editada, pode ser vista como uma forma de censura" (Jensema et al. 258 apud Szarkowska et al. 185), por outro, os teóricos da legendagem defendem que a LSE deva ser editada, de acordo com uma velocidade de legenda apropriada, já que surdos podem apresentar dificuldades com legendas com uma velocidade de exibição rápida e não-editadas. (Szarkowska et al.).

${ }^{5}$ Para a autora, a não-literariedade da tradução em legendagem é algo largamente aceito e utilizado pela legendagem interlinguística. Entre os pesquisadores do Grupo LEAD, a partir do que já foi apontado por nossas pesquisas exploratórias (Franco \& Araújo; Araújo (a); Araújo (b); Araújo e Nascimento) acreditamos que a prática da LSE deva ser semelhante à prática da legendagem interlinguística tradicional. 
ou seja, soar naturais na língua de chegada, podem acontecer tanto no nível da palavra (por exemplo, ao utilizar sinônimos menores, transformar verbos compostos em simples, mudar a classe das palavras, etc.) quanto da oração (por exemplo, ao simplificar modalizadores, mudar sujeito de uma oração, transformar orações longas e/ou compostas em orações simples, etc.), sendo, muitas vezes, mais efetivas do que reduções totais (Diaz Cintas \& Remael).

A redução total, por sua vez, também chamada apenas de redução, é pautada por questões de redundância ou relevância do texto legendado, sendo uma estratégia que deve ser usada com moderação e atenção pelos legendistas. Assim como a condensação, pode ocorrer também no nível da palavra (com a retirada de modificadores, adjetivos e advérbios, palavras de função fática, elementos interpessoais e algumas repetições) e no da oração (orações com carga informacional pequena), esta nem sempre aconselhável (Diaz Cintas \& Remael).

Presentes em uma grande parte da prática da legendagem, as estratégias de redução e condensação podem causar problemas de coerência na legendagem, outro aspecto linguístico relevante. Conforme Diaz Cintas e Remael, a falta de coerência em legendagem acontece devido ao cruzamento confuso de referências ou transições irregulares, levando a um estilo telegráfico do texto, sentenças mal feitas, etc. Quando a redução ocorre, o legendista deve ficar ainda mais atento à lógica construída na interligação do texto escrito com os outros canais de informação disponíveis.

Em relação à coesão na legendagem, esta é construída a partir da relação com os outros canais de informação disponíveis ao espectador, atingindo-se, assim, uma coesão intersemiótica. No que diz respeito à coesão de elementos textuais na legendagem, quando se considera apenas os elementos escritos, temos usos de referência (uso de pronomes), escolha lexical (repetição), tempo verbal e uso de conectivos $^{6}$ (Diaz Cintas \& Remael).

${ }^{6}$ Para análise de coesão textual em legendagem, Moran adota a categorização proposta por Halliday e Hasan sobre referência, substituição, elipse e conjunção.

Cad. Trad., Florianópolis, v. 40, n⿳0 esp. 2, p. 97-124, set-dez, 2020. 
Na legendagem, 'gaps' (vazios; brechas) entre referentes e referências podem causar problemas na compreensão do produto audiovisual caso o leitor não tenha lido parte da legenda ou não se recorde do que havia na legenda anterior, questão ainda mais relevante dada à natureza múltipla de canais de informação no produto legendado (Moran). Para Moran, diferentemente do texto escrito, os espectadores de filmes legendados não podem voltar o texto para solucionar uma ambiguidade ou contextualizar determinado elemento coesivo. Dessa forma, a coesão por meio de repetição seria preferível por reduzir o esforço cognitivo que ocorre quando há vazios informacionais deixados por substituição, referência ou elipse no texto legendado, as quais dependem da referência mental do espectador.

Outro parâmetro linguístico presente na legendagem é o da segmentação, que diz respeito à divisão da fala traduzida em porções de texto escrito na parte inferior (normalmente) da tela (Araújo \& Assis), a qual pode ser do tipo linguística (em que a sintaxe, a semântica, a lexicogramática e a fonologia-fonética são levadas em consideração), do tipo retórica (em que o fluxo de fala é levado em consideração) e do tipo visual (em que o corte ou mudança de cena são levados em consideração) (Reid; Gottlieb; Karamitroglou; Ivarsson \& Carroll; Diaz Cintas \& Remael; Chaves; Araújo \& Assis; Assis).

A segmentação do tipo linguística, tipo de segmentação visto como mais influente para um bom processamento da legendagem tem sido tema de vários estudos descritivos (Vieira et al; Araújo \& Assis; Assis) e experimentais (Perego et al.; Monteiro \& Dantas; Vieira \& Araújo; Rajendran et al.) em legendagem, pode ocorrer tanto na divisão dos blocos de legenda ao longo do texto legendado, quanto entre linhas (também chamada de line break) (Diaz Cintas \& Remael).

7 A preferência pelo termo "linguística" (é comum também o uso do termo "gramatical" para esse tipo de segmentação, conforme utilizado por Reid foi proposta por Chaves (45) e acatada pelos pesquisadores do Grupo LEAD-UECE porque o tema em questão não envolve somente a gramática, mas também a semântica e a fonologia-fonética; além disso, o termo "gramatical” pode ser associado, também, a uma discussão mais normativa da língua (Assis, Araújo 160).

Cad. Trad., Florianópolis, v. 40, n⿳0 esp. 2, p. 97-124, set-dez, 2020. 
Segundo a literatura da área, a segmentação linguística auxilia um processamento mais rápido do texto audiovisual legendado caso siga diretrizes linguísticas que coloquem essa divisão de texto no "mais alto nível sintático possível” (Karamitroglou), ou seja, evitando-se quebras sintagmáticas e entre orações. Contudo, ainda é muito comum na prática da legendagem a preferência por dividir as legendas a partir da geometria (formato) das mesmas. Araújo e Assis (161-162) apontam três formatos para essa divisão: i) um semelhante ao de um retângulo, com cada linha de legenda apresentando quase o mesmo número de caracteres e ii) dois formatos que lembram um triângulo, em que há mais caracteres na linha de cima ou de baixo (Araújo \& Assis 161-162).

O Quadro 1 abaixa apresenta os três formatos:

Quadro 1 - Formato das legendas na tela

\begin{tabular}{|l|l|}
\hline Formato & Legendas \\
\hline Em forma de retângulo & $\begin{array}{l}\text { 0 guardinha me parou por causa } \\
\text { de uma bobagem da placa que caiu! }\end{array}$ \\
\hline $\begin{array}{l}\text { Em forma de triângulo com a linha de cima } \\
\text { maior }\end{array}$ & $\begin{array}{l}\text { Um tutuzinho de feijão, } \\
\text { um lombinho. }\end{array}$ \\
\hline $\begin{array}{l}\text { Em forma de triângulo com a linha de cima } \\
\text { menor }\end{array}$ & $\begin{array}{l}\text { [Deolinda] já imaginava, } \\
\text { por isso fiz o tutuzinho logo hoje. }\end{array}$ \\
\hline
\end{tabular}

Fonte: Araújo e Assis (162)

Segundo Karamitroglou, todos os formatos podem ser processados pelo espectador quando há uma boa segmentação das legendas, apesar de o ideal, em seu ponto de vista, ser o formato quadrangular, que possui normalmente até 37 caracteres em cada linha de legenda na TV. É com este formato que os espectadores estão mais acostumados.

\subsection{Os parâmetros técnicos da legendagem}

Em relação aos parâmetros técnicos da legendagem, estes podem ser de dimensão espacial ou temporal (Diaz Cintas \& Remael). 
Entre os espaciais, temos: número de linhas, posicionamento da legenda e número de caracteres por linha. Entre os temporais, por sua vez, temos a marcação e duração das legendas, sincronização, intervalo entre legendas, velocidade e tempo de exposição. Dentre os mais significativos, em nossa visão, para a questão da leitura de legendas estão o número de linhas, o número de caracteres, o posicionamento, marcação, sincronização, intervalo entre legendas, tempo de exposição e velocidade da legenda.

No que diz respeito ao número de linhas, há um consenso na prática da legendagem de um número máximo de duas linhas por inserção de legenda, enquanto Diaz Cintas e Remael apontam que, apesar de o número máximo normalmente utilizado na prática da legendagem (interlinguística) para ouvintes ser de duas linhas, a LSE normalmente permite o uso de três e quatro linhas, como no Teletexto, sistema espanhol de LSE. Este número se assemelha ao utilizado no Brasil no contexto do closed caption $^{8}$. Há ainda o caso de legendas de apenas uma linha a partir do gênero do produto audiovisual, como é recomendado pelos pesquisadores do grupo LEAD para partidos políticos no Brasil (Araújo). No entanto, essa recomendação parte de pesquisas exploratórias. Atualmente, o grupo LEAD tem testado experimentalmente como o efeito sintático em legendas de uma linha e duas influenciam o processamento linguístico dos espectadores.

Apesar de timidamente, o número de linhas e sua influência no processamento de legendas já foi tema de investigações, como em d'Ydewalle et al. e De Bruycker e d'Ydewalle. Estes dois estudos, utilizando-se de uma metodologia baseada no uso de rastreamento ocular, que será discutida com mais detalhes adiante, apontaram um processamento mais confortável em legendas de duas linhas.

8 Tipo de legendagem fechada ou oculta acessada pelo controle remoto e destinada ao público surdo e ensurdecido, primariamente, na programação da TV no Brasil. Segue os princípios do sistema americano homônimo, funcionando a partir a transformação da legenda em códigos eletrônicos que são inseridos na linha 21 do intervalo vertical em branco da TV, sendo esta uma barra horizontal posta entre as imagens (Araújo (b)).

Cad. Trad., Florianópolis, v. 40, nº esp. 2, p. 97-124, set-dez, 2020. 
No que tange ao posicionamento das legendas, estas são alinhadas à esquerda ou centralizadas na parte inferior da tela com mais frequência. No caso da LSE no Brasil, aparece das duas formas, ainda podendo se movimentar em tela para acompanhar o personagem em tela (Assis). Ainda sobre o que deveria ser o posicionamento ideal da legenda, Diaz Cintas e Remael afirmam que a motivação de se preferir a parte central da tela para a alocação da legenda tem a ver com o fato de a ação se desenrolar, normalmente, no meio da tela (Diaz Cintas \& Remael 88). Além disso, d'Ydewalle et al. apontam que, como é natural os olhos de espectadores ocidentais focarem no centro da tela, as legendas centralizadas diminuem o palmo de movimento entre legenda e imagem.

A marcação e a sincronização são dois aspectos interrelacionados. Enquanto a marcação da legenda deve respeitar o ritmo da fala em tela, considerando o momento inicial e final de cada turno de fala, a sincronização diz respeito à harmonização entre o áudio do texto de partida e a legendagem, texto de chegada (Diaz Cintas \& Remael). Mesmo sendo um ponto crucial na caracterização da legendagem, a sincronização pode ser um pouco comprometida em detrimento de estratégias de redução linguística que venham auxiliar na adequação aos limites de caracteres do texto legendado, principalmente na LSE (Diaz Cintas \& Remael).

$\mathrm{O}$ intervalo entre legendas, normalmente de 80 a 120 milissegundos ${ }^{9}$, é aconselhado, uma vez que os olhos podem ter dificuldade de perceber a nova inserção de legenda (Diaz Cintas \& Remael). A outra justificativa seria um espaço para formação de inferências durante o processamento, o qual Just e Carpenter (336) chamam de encapsulamento (wrap-up effects), ou seja, durante a leitura, inferências são construídas nas relações entre as orações. Assim, qualquer inconsistência sobressai na duração da última fixação na legenda, que por isso tende a ser sempre mais longa do que as fixações anteriores. Nesse momento, o espectador pode não notar a

${ }^{9} \mathrm{O}$ grupo LEAD adota uma métrica de 100 milissegundos de intervalo entre legendas.

Cad. Trad., Florianópolis, v. 40, n⿳0 esp. 2, p. 97-124, set-dez, 2020. 
entrada da próxima legenda e assim não iniciar a leitura, conforme os estudos de Vieira.

O tempo de exposição em tela, por sua vez, foi determinado a partir de estudos experimentais com rastreamento ocular (d'Ydewalle et al.), os quais deram origem à regra dos 6 segundos (six-second rule); esta regra estabelece que a legenda deve ficar em tela por um tempo mínimo de 1 segundo (para que a legenda não "pisque em tela") e máximo de 6 (para que a legenda não fique em tela mais do que o tempo necessário de ser processada, ocasionando releituras) (Diaz Cintas \& Remael, 89-90). No Brasil, os legendistas usam a regra do quatro segundos que também foi considerada confortável pelos estudos de d'Ydewalle et al.

O número de caracteres por linha varia dependendo da mídia (cinema, festival de filme, DVD, TV, etc.), assim como pelo software de legendagem utilizado e dos contratantes do serviço. Diaz Cintas e Remael afirmam que podem existir legendas com um número de 37 caracteres (para TV) até 43 caracteres (em festivais de cinema). Segundo a regra dos seis segundos (d'Ydewalle et al.), um leitor pode ler confortavelmente até 74 caracteres em um bloco de legenda (37 caracteres por linha), o que estaria de acordo com o que é praticado na TV, segundo Diaz Cintas e Remael.

A velocidade da legenda é uma relação do tempo que ele fica exposto em tela com a quantidade de texto que a legenda possui. Diaz Cintas e Remael apresentam três tabelas de velocidade de legenda estabelecida a partir do software de legendagem Wincaps: 145 palavras por minuto (ppm), 160ppm e $180^{10}$, três velocidades de legenda normalmente utilizadas na legendagem profissional. Uma velocidade de 145 palavras por minuto (ou cerca de 2.5 palavras por segundo) seria uma velocidade baixa e confortavél em que, em até 6 seis segundos, poderia existir uma legenda cheia de 74 caracteres.

\footnotetext{
${ }^{10}$ Essa velocidade de leitura em palavras por minuto é transformada em caracteres por softwares de legendagem a partir da relação frame (quadros) e espaço disponível para legendagem (a cada dois frames, 1 espaço para legendagem) (Diaz Cintas \& Remael 97).
}

Cad. Trad., Florianópolis, v. 40, $\mathrm{n}^{0}$ esp. 2, p. 97-124, set-dez, 2020. 
Há uma relação entre o tempo em que a legenda deve ficar disponível em tela (levando em consideração o seu número de caracteres) e a velocidade de leitura dos espectadores para a legendagem. Sobre isso, Diaz Cintas e Remael (96) apontam que, ao se pensar sobre a velocidade de leitura ideal para determinado grupo, há que se ter em mente que, além da leitura das legendas, o público-alvo tem que ter tempo de processar a imagem em cena. Esse tempo de leitura, inclusive, pode ser dificultado pelo uso de um vocabulário obscuro (palavras com pouca frequência) ou uma sintaxe complicada.

Ainda em relação à velocidade da leitura da legenda, Ivarsson e Carroll (131) dizem que "a velocidade leitora difere grandemente entre o público ouvinte e isso se aplica a uma extensão ainda maior para os surdos e ensurdecidos ${ }^{11}$ ". Contudo, isso está mais relacionado ao letramento que os surdos têm naquela língua da legenda (normalmente sua L2, tendo a língua de sinais de seu país como L1) do que a uma condição de surdez em si. Essa percepção de uma forma geral fez com que as legendas para pessoas surdas e ensurdecidas fossem comumente feitas com uma velocidade menor (e, para isso, dependendo da velocidade de fala do filme, mais estratégias de redução linguística se fazem necessárias) em relação à legenda para ouvintes. No entanto, os estudos de Vieira e Araújo; Vieira et al. com espectadores surdos e ouvintes assistindo a um documentário legendado e tendo os olhos rastreados revelaram que as legendas rápidas, para os dois grupos, pareceram ser mais favoráveis durante o processamento.

Relacionado a essa necessidade de se investigar parâmetros tidos como dados na literatura em legendagem, visto que muito do que se pratica na legendagem profissional partiu da atividade de profissionais da área não da recepção/processamento da legenda pelo seu público-alvo, o grupo LEAD passou a realizar pesquisas exploratórias e experimentais com rastreamento ocular de modo a

11 Nossa tradução de: Viewer reading speeds differ greatly among hearing audiences and this applies to an even greater extent to the deaf and hard of hearing.

Cad. Trad., Florianópolis, v. 40, nº esp. 2, p. 97-124, set-dez, 2020. 
definir os aspectos necessários para um melhor processamento de LSE por surdos e ensurdecidos brasileiros. Alguns desses estudos serão discutidos na próxima seção.

\section{Estudos exploratórios sobre LSE no Brasil}

Os estudos a seguir mostram como os parâmetros de velocidade e segmentação podem influenciar no processamento e compreensão das legendas por parte dos espectadores surdos/ensurdecidos. Assim, seguimos uma ordem cronológica desde os primeiros trabalhos desenvolvidos pelo grupo LEAD da Universidade Estadual do Ceará (UECE) até o presente momento.

O primeiro estudo sobre a LSE no âmbito do LEAD, descrito em Franco e Araújo, teve como participantes 15 surdos de nascença do Instituto Cearense de Educação de Surdos do Ceará (ICES) e 13 ouvintes. Esse estudo propôs uma análise da LSE veiculada na Rede Globo testando, principalmente, questões relativas à sincronia fala, legenda e imagem. Os resultados mostraram que a falta de harmonia entre os três elementos em questão causou dificuldades na compreensão do filme legendado pelos participantes, o que está em acordo com o que era previsto na literatura da área (Diaz Cintas \& Remael). Contudo, uma das hipóteses do estudo, que pressupunha que sempre que houvesse sincronia entre fala, legenda e imagem, a recepção por parte do espectador surdo seria facilitada, foi refutada. Como alguns surdos não entenderam o conteúdo do filme mesmo com esse parâmetro, os pesquisadores levantaram a possiblidade de que talvez a falta de edição (redução linguística) tivesse atrapalhado o processamento dos participantes.

Para investigar essas pressuposições, foi realizado o segundo estudo (Araújo (a)). Este consistiu de três estágios: relegendagem dos programas da Globo; reelaboração do questionário, agora com questões abertas e fechadas, diferentemente das questões de múltipla escolha que causaram um pouco de confusão entre os surdos no estudo anterior, e a pesquisa em si. Dessa vez, o questionário continha 
questões sobre os aspectos de conteúdo, imagem e detalhes (De Linde \& Kay), de modo a avaliar o entendimento do filme englobando a compreensão da legenda e da imagem. Apesar de resultados melhores do que no primeiro estudo, os resultados ainda não foram considerados satisfatórios, pois alguns participantes entendiam o conteúdo, mas não mencionavam os detalhes ou as imagens, e vice-versa.

No terceiro estudo (Araújo (b)), o foco foi uma reedição ainda maior das legendas. Nesse estudo, participaram 12 surdos vinculados ao Centro de Apoio ao Surdo (CAS), que assistiram aos mesmos programas legendados pela Rede Globo e pela equipe de legendagem, sendo a legenda desta vez baseada nos padrões de edição da legenda para ouvintes, mas com o acréscimo de informações adicionais necessárias aos surdos entre colchetes. A partir dessas seções, filmadas com o depoimento em LIBRAS e a mediação de um intérprete, algumas questões sobre o formato ideal para a legenda para surdos, assim como a velocidade de 145 palavras por minuto, foram sugeridas: 1) a cor deve ser amarela em um fundo transparente; 2) a identificação de falantes e os efeitos sonoros devem aparecer entre colchetes; 3) a voz filtrada (voz fora da tela, vinda da televisão, por exemplo) deve estar em itálico; e 4) a linguagem utilizada deve ser o português formal.

Dando prosseguimento a esse percurso de pesquisas exploratórias com LSE no país, um estudo nacional com 34 surdos em 4 regiões brasileiras (Araújo \& Nascimento) foi realizado de forma a testar se os parâmetros estabelecidos pelos surdos cearenses nas três pesquisas supracitadas seriam confirmados ou refutados.

A pesquisa em questão buscou checar as seguintes hipóteses: 1) quando a velocidade da legenda é de $145 \mathrm{ppm}$, os surdos conseguem entender o conteúdo do filme, bem como seus detalhes; 2) quando a velocidade de legenda é de 160ppm, os surdos conseguem entender o conteúdo do filme, mas não os seus detalhes; 3) quando a velocidade da legenda é de 180ppm, os surdos não conseguem entender o conteúdo do filme e tampouco os detalhes; 4) quando o sistema português de legendagem é utilizado (cor branca para as falas e amarela para identificação dos falantes e efeitos sonoros, 
além da movimentação em tela para acompanhar o personagem que detém o turno de fala), a recepção é dificultada.

A primeira hipótese da pesquisa foi confirmada, tendo os surdos entendido o filme, bem como seus detalhes, com a velocidade de $145 \mathrm{ppm}$. Tanto no filme que testou essa hipótese, quanto nos outros filmes, alguns detalhes que não foram mencionados não estavam diretamente relacionados à velocidade da legenda ou ao sistema de legendagem, mas a outros fatores, como conhecimentos acerca do gênero do filme, por exemplo. Essa velocidade de leitura de 145ppm foi considerada ideal pelos surdos do CAS e eles demonstraram uma boa compreensão do conteúdo dos vídeos.

Quanto à segunda hipótese, que dizia que quando a velocidade de legenda fosse de 160ppm, os surdos conseguiriam entender o conteúdo do filme, mas não os seus detalhes, ela foi refutada. Os surdos tiveram uma compreensão do conteúdo das legendas tão eficiente quanto na legendagem com a velocidade de $145 \mathrm{ppm}$, considerada ideal.

A terceira hipótese, da mesma forma, foi refutada. Esta dizia que, quando a velocidade da legenda fosse de 180ppm, os surdos não conseguiriam entender o conteúdo do filme e tampouco os seus detalhes. Contudo, os surdos, de uma forma geral, tiveram uma compreensão bastante satisfatória do filme que testava essa hipótese.

A quarta hipótese, sobre a dificuldade na recepção do modelo português de legendagem, apesar de os participantes terem reclamado bastante, de uma forma geral, das legendas que se movem para acompanhar o falante e do uso de cores para diferenciar fala e informações adicionais (identificação de falante e efeito sonoro), também foi refutada, visto que os surdos tiveram uma recepção eficiente para este tipo de legendagem. O estranhamento, segundo Araújo e Nascimento, estaria mais relacionado à falta de costume da comunidade surda brasileira com esse tipo de legendagem do que a uma impossibilidade de se utilizar esse sistema de LSE.

Os resultados de Araújo e Nascimento sugeriram que, ao invés da velocidade da legenda e da edição linguística necessária para a adequação às velocidades da legenda (145, 160 e 180ppm), talvez o parâmetro da segmentação linguística fosse o principal responsá- 
vel pelo processamento bem-sucedido dos filmes legendados pelos espectadores surdos.

Dando continuidade às pesquisas no âmbito do grupo LEAD, vários estudos descritivos com foco na segmentação foram realizados (Chaves; Araújo \& Assis; Arraes; Assis), os quais identificaram uma grande quantidade de problemas de segmentação linguística, principalmente na programação closed caption da TV brasileira.

Contudo, ainda faltavam estudos que examinassem a LSE (como um todo e, principalmente, o parâmetro da segmentação linguística) de forma mais objetiva, com o auxílio de metodologias experimentais que confirmassem ou refutassem com mais precisão a influência de parâmetros da legendagem no processamento de legendas por participantes surdos. Assim, o próximo passo foi a criação do Projeto ExLeg (Estudos Experimentais em Tradução Audiovisual para Surdos: Análise da Velocidade e da Segmentação), que propôs o uso de rastreamento ocular para investigação do processamento de legendas.

A seção a seguir discorre sobre os primeiros resultados usando o rastreamento ocular na investigação com espectadores surdos e ouvintes sobre o processamento da segmentação linguística e da velocidade na LSE durante a recepção de um documentário.

\section{LSE e estudos com rastreamento ocular}

Como as pesquisas exploratórias apontavam que as velocidades da legendagem de 160 e 180ppm não comprometiam a compreensão dos conteúdos dos vídeos testados, tínhamos agora como hipótese a segmentação linguística, uma vez que ela é considerada um parâmetro importante pelos teóricos em legendagem (Karamitroglou; Diaz Cintas \& Remael).

O primeiro estudo experimental realizado pelo projeto ExLeg testou a segmentação linguística e a velocidade de legendas em um documentário com espectadores surdos e ouvintes, usando a técnica do rastreamento ocular. 
Esta pesquisa contou com a participação de 8 surdos sinalizadores fluentes da Libras e leitores da língua portuguesa e 8 ouvintes falantes da língua portuguesa. Os dois grupos apresentavam idades entre 19 a 41 anos. Quanto à escolaridade, eram graduados ou graduandos. Os surdos apresentam surdez pré-linguística e o teste audiométrico informou que eles apresentavam surdez profunda. Todos os participantes informaram que costumavam assistir a filmes legendados em português.

Este estudo englobou as seguintes hipóteses: 1. Tanto na velocidade da LSE lenta (145ppm) quanto na rápida (180ppm), o processamento dos surdos e ouvintes não seria prejudicado quando houvesse uma boa segmentação linguística; 2 . Tanto na velocidade da LSE lenta $(145 \mathrm{ppm})$ quanto na rápida $(180 \mathrm{ppm})$, o processamento dos surdos e ouvintes seria prejudicado quando houvesse uma má segmentação linguística.

O estímulo utilizado nos testes foi um documentário produzido pela Rede Globo de televisão chamado Globo Repórter com legendas manipuladas respeitando as seguintes condições: 1) Lenta e Bem Segmentada (LBS); 2) Lenta e Mal Segmentada (LMS); 3) Rápida e Bem Segmentada (RBS) e 4) Rápida e Mal Segmentada (RMS). Os vídeos que foram usados nos testes tinham o mesmo tempo - 1 minuto. Todos os participantes foram expostos a vídeos sem som. A seguir, no Quadro 2, apresentamos um exemplo de como foram manipuladas as legendas de acordo com as condições experimentais:

Quadro 2: Exemplo de manipulação das legendas

\begin{tabular}{|l|l|l|l|}
\hline Condição & Tempo & Caracteres & Legenda \\
\hline Lenta e bem segmentada & $3,8 \mathrm{~s}$ & $17+31=48$ & $\begin{array}{l}\text { Vizinhos marcados } \\
\text { por anos de guerra e isolamento }\end{array}$ \\
\hline Lenta e mal segmentada & $3,8 \mathrm{~s}$ & $21+27=48$ & $\begin{array}{l}\text { Vizinhos marcados por } \\
\text { anos de guerra e isolamento }\end{array}$ \\
\hline
\end{tabular}

Fonte: Elaborado pelos autores. Adaptado de Vieira et al. 
O exemplo acima (quadro 2) mostra a mesma legenda nas duas condições bem e mal segmentada. A diferença está na quebra entre linhas da mesma legenda, uma quebra na ordem do sintagma preposicional, separando o núcleo do sintagma 'por' do substantivo 'anos' que funciona como seu complementador; a bem segmentada, por sua vez, respeita os sintagmas e a mal apresenta uma quebra exatamente entre os termos de um mesmo sintagma. As legendas de velocidade mais rápida $(180 \mathrm{ppm})$ apresentam maior número de caracteres para um tempo menor quando comparadas as legendas lentas (145ppm).

Para compreendermos como a segmentação e a velocidade poderiam ser custosas aos participantes, o estudo foi analisado tendo duas fontes de dados distintas: os dados obtidos pelo rastreador ocular e as respostas dos participantes quanto ao conteúdo dos vídeos. Além disso, a avaliação dos participantes sobre a LSE dos vídeos foi levada em consideração.

O estudo teve como desenho o quadrado latino proposto por Marquer. Nele, cada participante é exposto a todas as condições experimentais e todas as condições são testadas por participantes diferentes.

Após a recepção de cada vídeo, os participantes respondiam a dois questionários: 1. Resumo sobre o conteúdo dos vídeos; 2. A avaliação sobre a velocidade das legendas ou se algo os perturbou durante a recepção.

Nesse estudo experimental/exploratório, os dados revelaram que a velocidade pode influenciar sim o processamento de espectadores surdo, no entanto, diferentemente do que preconizávamos nas primeiras pesquisas, os surdos deste estudo demonstraram que as legendas rápidas favorecem mais o processamento e a compreensão do que as legenda lentas.

Estatisticamente (ANOVA), tanto os surdos quanto os ouvintes têm um tempo de processamento de leitura mais baixo nas legendas na condição RBS. Isso significa que o processamento é menos custoso se as legendas estiverem na velocidade rápida (180ppm). Esses dados refutaram nossa primeira hipótese de que as legendas 
na condição lenta e bem segmentada teriam uma recepção eficiente para os dois grupos. O curioso é que o fato de ser lenta e bem segmentada não facilitou o processamento dos surdos, uma vez que as médias de duração das fixações foram maiores nas condições lentas e com uma diferença entre a bem e a mal segmentada insignificante, 300ms (LBS) e $299 \mathrm{~ms}$ (LMS).

O estudo estatístico das fixações geradas pelo caminho do olhar nas legendas de duas linhas mostrou um efeito significativo em relação à influência da segmentação linguística no comportamento ocular. Quando interagimos as variáveis grupo vs segmentação vs velocidade $(\mathrm{F}[3,60]=5,1844, \mathrm{p}<0.05)$, o efeito da segmentação se revelou. Ou seja, os grupos de participantes, quando expostos a legendas mal segmentadas, tendem a processá-las de forma mais custosa. Logo, este resultado foi diferente do de Perego et al., os quais afirmaram que não encontraram evidências de perturbação na recepção de legendas com quebra indevida no sintagma nominal. No entanto, devemos levar em consideração que os autores apresentaram um gênero e um desenho experimental diferentes desta pesquisa. Como não testamos um sintagma específico e o gênero também foi diferente, provavelmente esses fatores podem ter contribuído para resultados diferentes entre as duas pesquisas.

O segundo método do estudo - exploratório, pelos questionários, revelou-nos também muito sobre a compreensão dos participantes. Surdos e ouvintes, no geral, relataram o conteúdo dos vídeos bem como os detalhes em todas as condições. No entanto, os surdos apresentavam mais detalhes sobre o conteúdo quando as legendas estavam na condição RBS, corroborando assim os dados estatísticos fornecidos pelo rastreador ocular. Isso novamente nos revelou que a velocidade das legendas não foi um entrave para a compreensão dos vídeos, como aconteceu nos resultados do projeto MOLES (Araújo et al.).

Assim, tanto os dados experimentais quanto os exploratórios refutaram em parte nossa hipótese de que as legendas na velocidade lenta $(145 \mathrm{ppm})$ e bem segmentada não prejudicaria a compreensão dos dois grupos. Para os surdos, a condição LBS levou um tempo 
de processamento muito próximo da condição RMS, demonstrando algum tipo de desconforto. No entanto, os participantes surdos não fizeram nenhuma reclamação quanto aos problemas técnicos da condição LBS, mas não chegavam a fornecer tantos detalhes como na condição RBS.

Também observamos se o efeito de encapsulamento nas legendas nos revelaria como a segmentação e a velocidade influenciaram no processamento. Para Just e Carpenter, se ocorreu algum problema durante a leitura que dificulte o processamento das palavras, ficará evidente na última fixação. Dessa forma, observamos a média de duração das últimas fixações em cada condição experimental, conforme a tabela 1 .

Tabela 1 - Duração média da última fixação por condição experimental

\begin{tabular}{lll}
\hline Condições & $\begin{array}{l}\text { Duração da última fixação } \\
\text { (ouvintes) }\end{array}$ & $\begin{array}{l}\text { Duração da última fixação } \\
\text { (surdos) }\end{array}$ \\
\hline LBS & 351,03 & 422,30 \\
LMS & 456,98 & 438,17 \\
RBS & 365,50 & 344,21 \\
RMS & 340,45 & 400,91 \\
\hline
\end{tabular}

Fonte: Vieira.

Conforme a Tabela 1, a má segmentação linguística influenciou o aumento da duração do encapsulamento na condição LMS para os ouvintes e para os surdos nas duas condições mal segmentadas (LMS e RMS). Isso, por consequência, causou atrasos na próxima fixação das legendas, aumentando o número de perdas de legendas durante a leitura. Ou seja, as considerações de Just e Carpenter, sobre a influência de como os problemas sintáticos e estruturais podem afetar a duração da última fixação, foram mais evidentes no comportamento leitor dos surdos em relação às condições mal segmentadas. 
Voltando as nossas hipóteses, assim como o projeto MOLES (Araújo et al.), a hipótese de que a segmentação linguística perturba, independente da velocidade, foi confirmada, tanto pelos dados gerados pelo comportamento do olhar como pela parte exploratória.

Durante a leitura, o olhar faz um caminho da esquerda para a direita; quando encontramos retornos (movimentos regressivos) da direita para a esquerda, temos um indicador de que ocorreram falhas durante a leitura e esses movimentos tentam compensá-las (Rayner \& Liversedge). Conforme Vieira et al., os dois grupos apresentaram mais movimentos regressivos nas condições em que as legendas estavam mal segmentadas. Os resultados estatísticos (ANOVA) em relação à duração dos movimentos regressivos dos dois grupos, na interação grupo vs segmentação vs velocidade, mostraram efeito de significância $[\mathrm{F}(3,60)=5,21, \mathrm{p}<0,05]$. Isso explica que a má segmentação influenciou na duração dos movimentos regressivos para os participantes (Vieira et al.).

Logo, a segmentação linguística influenciou no número de fixações, na duração das fixações, na duração do encapsulamento e nos movimentos regressivos.

Dessa forma, acreditamos que o investimento em pesquisas experimentais com rastreamento ocular sobre o processamento linguístico de legendas poderá contribuir para que possamos compreender esse universo, avaliando a influência dos parâmetros linguísticos durante a recepção audiovisual por espectadores surdos.

\section{Considerações Finais}

O processamento de produtos legendados não ocorre como no processamento de um texto escrito qualquer; devido aos múltiplos canais de informação que são responsáveis carregar significado no produto legendado (podendo conter texto verbal escrito, texto verbal oral, som e imagem), o processamento do texto verbal escrito na legendagem é mais custoso pela própria natureza do gênero, pois ele tem que dividir espaço com outras semioses. 
Além disso, o fato de o texto legendado escrito ser limitado por características técnicas (número de linhas, tempo de exposição mínimo e máximo, número de caracteres por linha, etc.) faz com que esse processamento seja condicionado por diversos fatores. Um equilíbrio entre os parâmetros técnicos e linguísticos da legendagem (e também paralinguísticos, no caso da LSE) permite um processamento mais confortável do texto legendado.

Em relação aos parâmetros preconizados na prática da LSE, é interessante notar como em sua maioria são pautados pela prática profissional da área e não por pesquisas. O percurso de pesquisa sobre LSE no Brasil no âmbito Grupo LEAD tem utilizado diversas metodologias (exploratória, descritiva e, ultimamente, experimental) de modo a basear as escolhas tradutórias cada vez mais em pressupostos advindos da observação e estudo dos fenômenos desse tipo de tradução audiovisual acessível.

Ao colocar mais ênfase na pesquisa experimental baseada na utilização de rastreamento ocular nos últimos anos, temos observado com mais precisão como acontece a leitura da LSE por surdos brasileiros, corroborando com achados anteriormente sugeridos pelas pesquisas exploratórias e descritivas, como é o caso da relevância do parâmetro da segmentação linguística. Contudo, ainda é grande o caminho a ser trilhado, pois um maior número de gêneros (filmes, telenovelas, seriados, telejornais, etc.), de parâmetros (número de linhas, redução linguística, sincronia, etc.) e participantes faz-se necessário para que consigamos compreender melhor a natureza do processamento de LSE e, dessa forma, oferecer produtos legendados com maior qualidade e que demandem menos custo de processamento para essa parcela da população. 


\section{Referências}

Araújo, Vera Lúcia Santiago (a). "Closed subtitling in Brazil". Topics in audiovisual translation, Orero, Pilar, (Ed.). Vol. 56. Amsterdam: John Benjamins Publishing, 2004, pp. 199-212.

Araújo, Vera Lúcia Santiago (b). "Por um modelo de legendagem para Surdos no Brasil". Tradução \& Comunicação, Revista Brasileira de Tradutores. 17, (2008): $59-76$.

Araújo, Vera Lúcia Santiago (c). "In search of SDH parameters for Brazilian party political broadcasts". The Sign Language Translator and Interpreter. 3.2, (2009): 157-167.

Araújo, Vera Lúcia Santiago; Nascimento, Ana Katarinna Pessoa. "Investigando parâmetros de legendas para surdos e Ensurdecidos no Brasil". Tradução em Revista. 2, (2011): 1-18.

Araújo, Vera Lúcia Santiago; Vieira, Patrícia Araújo; Monteiro, Silvia Malena Modesto. "Legendagem para surdos e ensurdecidos (LSE): um estudo de recepção com surdos da região Sudeste”. TradTerm 22, (2013): 283-302.

Araújo, Vera Lúcia Santiago; Assis, Ítalo Alves Pinto de. "A segmentação na legendagem para surdos e ensurdecidos (LSE) de Amor Eterno Amor: uma análise baseada em corpus". Letras \& Letras. 30.2, (2014): 156-184.

Arraes, Daniel. Legendagem para surdos e ensurdecidos: análise baseada em corpus da segmentação linguística do filme "Virada Radical". Monografia (Bacharelado em Letras Inglês) - Universidade Estadual do Ceará, Fortaleza, 2015.

Assis, Ítalo Alves Pinto. Legendagem para surdos e ensurdecidos (LSE): análise baseada em corpus da segmentação linguística em "Amor Eterno Amor". Dissertação de Mestrado em Linguística Aplicada, Universidade Estadual do Ceará, UECE, Fortaleza, 2016. 
Chaves, Élida Gama. Legendagem para surdos e ensurdecidos: um estudo baseado em corpus da segmentação nas legendas de filmes brasileiros em DVD. Dissertação de Mestrado em Linguística Aplicada, Universidade Estadual do Ceará, UECE, Fortaleza, 2012.

De Linde, Zoé; Kay, Neil. The semiotics of subtitling. Manchester: St. Jerome Publishing, 1999.

Diaz Cintas, Jorge; Remael, Aline. Audiovisual translation: subtitling. Manchester, UK, Kinderhook, NY, UK: St. Jerome Publishing, 2007.

De Bruycker, Wim; d'Ydewalle, Géry. "Reading native and foreign language television subtitles in children and adults". The mind's eye: Cognitive and applied aspects of eye movement research, Radach, Ralph; Jukka Hyona and Heiner Deubel. (Eds.). Amsterdam: Elsevier, 2003, pp. 671-684.

d'Ydewalle, Géry; Rensbergen, Johan Van; Pollet, Joris. "Reading a message when the same message is available auditorily in another language: The case of subtitling”. Eye Movements from Physiology to Cognition, O'Regan, J. Kevin and Ariane Levy-Schoen. (Eds.). Amsterdam: Elsevier, 1987, pp. 313-321.

Franco, Eliana P.C.; Araújo, Vera Lucia Santiago. "Reading television: Checking deaf people's reactions to closed subtitling in Fortaleza, Brazil". The Translator. 9.2, (2003): 249-267.

Gottlieb, Henrik. "Subtitling: diagonal translation". Perspectives: studies in translatology. 2.1, (1994): 101-121.

Ghia, Elisa. "The impact of translation strategies on subtitle reading". Eye tracking in audiovisual translation. (2012): 157-182.

Ivarsson, Jan; Carroll, Mary. Subtitling. Simrishamn: TransEdit, 1998.

Jakobson, Roman. "On linguistic aspects of translation". On translation, Brower, Reuben A. (Ed.). MA: Harvard University Press, 3, 1959, pp. 232-239. 
Just, Marcel A.; Carpenter, Patricia A. "A theory of reading: From eye fixations to comprehension”. Psychological review. 87.4, (1980): 329.

Karamitroglou, Fotios. "A proposed set of subtitling standards in Europe". Translation journal. 2.2, (1998): 1-15.

Marquer, Pierre. "La méthode experimentale: quelques points de repère". La psychologie cognitive. Paris: Armand Colin. (2003): 185-206.

Moran, Siobhan. "The effect of linguistic variation on subtitle reception". Eye tracking in audiovisual translation. (2012): 183-222.

Monteiro, Silvia Malena Modesto; Dantas, João Francisco. “Tradução audiovisual acessível (TAVa): a segmentação linguística na Legendagem para Surdos e Ensurdecidos (LSE) da campanha política na televisão em Fortaleza”. Trabalhos em Linguística Aplicada. 56.2, (2017): 527-560.

Neves, Josélia. Audiovisual translation: Subtitling for the deaf and hard-ofhearing. Doctoral Dissertation. Roehampton University, 2005.

Perego, Elisa; et al. "The cognitive effectiveness of subtitle processing”. Media psychology. 13.3, (2010): 243-272.

Szarkowska, Agnieszka; et al. "The effects of text editing and subtitle presentation rate on the comprehension and reading patterns of interlingual and intralingual subtitles among deaf, hard of hearing and hearing viewers". Across Languages and Cultures. 17.2, (2016): 183-204.

Szarkowska, Agnieszka; Gerber-Morón, Olivia. "Two or three lines: a mixedmethods study on subtitle processing and preferences". Perspectives. 27.1, (2019): 144-164.

Reid, Helene. "Literature on the screen: subtitle translation for public broadcasting”. Something understood: studies in Anglo-Dutch literary translation, Westerweel, Bart, and Theo d'Haen. (Eds.). Vol. 5, Amsterdam: Rodopi, (1990): 97-107. 
Rajendran, Dhevi J.; et al. "Effects of text chunking on subtitling: A quantitative and qualitative examination". Perspectives. 21.1, (2013): 5-21.

Rayner, Keith; Liversedge, Simon P. "Visual and linguistic processing during eye fixations in reading". The Interface of Language, Vision and Action: Eye Movements and the Visual World, Ferreira, Fernanda and John M. Henderson. (Eds.). London: Psychology Press, 2004, pp. 56-104.

Vieira, Patrícia Araújo; et al. “A segmentação na legendagem do documentário Globo Repórter: uma análise baseada em corpus”. A tradução e suas interfaces: múltiplas perspectivas, Cunha, R.B and E.P Carvalho. (Eds.). Curitiba: Editora CRV, 2015, pp. 65-85.

Vieira, Patrícia Araújo. A influência da segmentação e da velocidade na recepção de legendas para surdos e ensurdecidos (LSE). Tese de Doutorado, Programa em Pós-Graduação em Linguística Aplicada, Universidade Estadual do Ceará, 2016.

Vieira, Patrícia Araújo; Teixeira, Elisângela Nogueira; Chaves, Élida Gama. "Caminhos do Olhar: A Movimentação Ocular de Espectadores Surdos durante a Exibição de Vídeos Legendados". Trabalhos em Lingüística Aplicada. 56.2, (2017): 493-526.

Vieira, Patrícia Araújo; Araujo, Vera Lúcia Santiago. “A influência da segmentação linguística na recepção de legendas para surdos e ensurdecidos (LSE) em documentários televisivos”. Domínios de Lingu@gem. 11.5, (2017): 1797-1824.

Recebido em: 20/09/2020

Aceito em: 05/11/2020

Publicado em dezembro de 2020

Patrícia Araújo Vieira. E-mail: pattivieira477@gmail.com. ORCID: https:// orcid.org/0000-0001-6611-720X

Ítalo Alves Pinto de Assis. E-mail: italoalves1991@gmail.com. ORCID: https:// orcid.org/0000-0001-8571-3592

Vera Lúcia Santiago Araújo. E-mail: verainnerlight@gmail.com. ORCID: https://orcid.org/0000-0002-4654-874 